HANDBOOK OF CLASSICAL AND MODERN MANDAIC 



\section{Rudolf Macuch}

\section{HANDBOOK \\ OF CLASSICAL AND \\ MODERN MANDAIC}

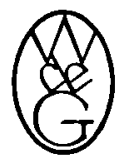

WALTER DE GRUYTER \& CO.

vormals G. J. Göschen'sche Verlagshandlung

J. Guttentag, Verlagsbuchhandlung - Georg Reimer - Karl J. Trübner - Veit \& Comp.

BERLIN r969 
(C)

Archiv-Nr. 4345 65/1

Copyright 1965 by Walter de Gruyter \& Co., vormals G. J. Göschen'sche Verlagshandlung - J. Guttentag, Verlagsbuchbandlung - Geotg Reimer - Karl J. Trübner - Veit \& Comp.

Printed in Germany. Alle Rechte der Ubersetzung, des Nachdrucks, der photomechanischen Wiedergabe und der Anfertigung von Mikrofilmen - auch auszugsweise - vorbehalten.

Satz und Druck: Walter de Gruyter \& Co., Berlin. 
To my respected and beloved Master

$$
\text { JÁN BAKOŠ, }
$$

Professor Emeritus of Semitic Languages

at Comenius' University in Bratislava

'thib lašualia auquria rba (DC 53, p. 5:16)

"Datum est discipulo honorare magistrum"

man "allamani harfan

qad sayyarani abdan (a Muslim tradition)

"Qui mihi verbum docuit

me sclavum suum reddidit" 
